\title{
Influence of dietary habits on thyroid status of a nomadic people, the Bororo shepherds, roaming a central African region affected by severe iodine deficiency
}

\author{
Paolo Biassoni, Giambattista Ravera ${ }^{1}$, Jone Bertocchi ${ }^{2}$, Federico Schenone ${ }^{3}$ and Pierre Bourdoux ${ }^{4}$ \\ Department of Internal Medicine, ${ }^{1}$ Institute of Statistics and Biometry, ${ }^{2}$ Civil Hospital of Ngaoundaye, Ngaoundaye, Central African Republic, \\ ${ }^{3}$ Nuclear Medicine IST, Institute for Cancer, University of Genoa, Genoa, Italy, and ${ }^{4}$ Laboratory of Pediatrics, Free University of Brussels, Brussels, Belgium \\ (Correspondence should be addressed to P Bourdoux, Université Libre de Bruxelles, Laboratoire de Pédiatrie, Hôpital Universitaire des Enfants, Avenue \\ J J Crocq 15, B-1020 Brussels, Belgium)
}

\begin{abstract}
Objective: In contrast with the endemic goiter reported in several African countries, the nomadic Bororos of the Central African Republic have an unexpectedly low prevalence of goiter. This study was conducted to elucidate this puzzling observation.

Design: Thyroid function and iodine and thiocyanate intakes were evaluated in Bororos and inhabitants of the same area and compared with an Italian population.

Results: Urinary iodine concentrations indicated moderate iodine deficiency in the rural people and the Bororos. In the latter, no individual with clinical hypothyroidism was observed. Compared with the reference population, the Bororos had slightly lower thyroxine $\left(\mathrm{T}_{4}\right)$ and free thyroxine $\left(\mathrm{FT}_{4}\right)$, slightly increased tri-iodothyronine $\left(\mathrm{T}_{3}\right)$ and $\mathrm{T}_{3} / \mathrm{T}_{4}$ ratio, slightly higher TSH, normal serum thyroglobulin, a prevalence of goiter of $17.1 \%$ and a higher urinary thiocyanate. The rural people showed striking differences: lower $\mathrm{T}_{4}$ and $\mathrm{FT}_{4}$, increased $\mathrm{T}_{3} / \mathrm{T}_{4}$ ratio, markedly increased TSH and thyroglobulin, a prevalence of goiter of $76.9 \%$ and a high urinary thiocyanate, indicating frequent consumption of cassava. A dietary survey indicated that the Bororos ingest large amounts of milk and related products but infrequently eat cassava.

Conclusion: A minute difference in iodine deficiency between two populations induces totally different patterns of goiter and thyroid function. The reason for such a contrast probably involves differences in diet.
\end{abstract}

European Journal of Endocrinology 138 681-685

\section{Introduction}

Endemic goiter now recognized as iodine deficiency disorders has been reported in several countries in Central and Western Africa (1). The awareness of iodine deficiency disorders has recently revealed that iodine deficiency in this part of Africa actually occurs in a belt from Mauritania in the west to Congo in the heart of the continent. High prevalences of goiter of up to $80 \%$ have been reported in these African countries where iodine deficiency prevails (1).

The link between goiter and iodine deficiency is well established. However, the reason why some individuals exposed to the same conditions of iodine deficiency develop a goiter whereas others do not is still not known. Undoubtedly, iodine deficiency is a permissive condition (2), but other nutritional and/or environmental conditions are instrumental. These may favour the induction of an enlargement of the thyroid gland or protect an individual from the effects caused by iodine deficiency.
Several nomadic tribes, including the Bororos, live in the Sahelian part of Africa. During a goiter survey carried out in the north western region (Ouham-Pende) of the Central African Republic, we were impressed by the low prevalence of goiter in the Bororos compared with the severity of goiter and cretinism evident in the rural populations (Pana, Baya, Mboum) living in the same area $(3,4)$. Our aim was therefore to evaluate the prevalence of goiter, to assess biochemical parameters related to thyroid function and to collect nutritional information about the Bororo population in order to understand this intriguing observation.

\section{Subjects and methods}

\section{The Bororos}

The Bororos are nomad shepherds living in the north western Sudanese area (Mali, Niger, North Cameroun and the Central African Republic). They belong to the 
family of Fulani, although their racial origins are still not clearly known. They probably belong to the Ethiopic kin which merged with Arabs and Negroid people after an ancient migration towards southern Egypt (5). However, their language is similar to 'seres' and 'wolof', two of the Senegalese dialects. This probably indicates a long stay in the western part of the African continent.

Their somatic traits and cultural traditions are quite different from those of Negroid people (6). Proud of their origins and culture, their tribe development is strictly endogamic.

They do not live in villages but in small family groups always moving around the savanna in search of the best forage for their cattle $(7,8)$. One of their well known migrations starts from the north western region of the Central African Republic continues towards the southern regions of Chad and Sudan and then returns to the eastern regions of the Central African Republic.

Their herds represent their personal fortunes and prestige. From these the Bororos draw their food: milk, cheese and blood. Adults ingest 1-2 liters of milk a day and use it to make cheese. They sometimes drink fresh blood drawn directly from the jugular vein of their beasts. Meat, however, is rarely consumed since they do not kill their animals. Cassava in doses of 300-350 g powder per day supplements their diet. It is bought or exchanged by the women when family groups encamp near villages in the Central African Republic during their migrations, since the Bororos do not cultivate this tuber. In contrast, for the local rural people, cassava is the staple food, and meat and milk are very rarely consumed. Cassava is generally boiled in water.

\section{Study subjects}

The study was conducted in the early $1990 \mathrm{~s}$ in the province of Ouham Pende in the north western part of the Central African Republic on the frontier with Cameroun and Chad. It was authorized by the Ministry of National Health. The populations were advised by leaders of the villages that the aim of our visit was to see everyone in each village to study the problem of goiter. To gather a sufficient number of subjects for the epidemiological survey, we asked for the help of the Bororos' spiritual chief who brought together his people from the camps in the savanna to five different villages: Ngaoundaye, Nzakoundou, Kounang, Ndim and Man.

Among the Bororos, 222 subjects (107 males and 115 females) aged 6 to over 45 years agreed to be examined by two of the authors (P B and F S). Samples of blood and urine were randomly drawn for determination of hormones, iodine and thiocyanate. After informed verbal consent, 84 subjects gave a urine sample; 47 subjects agreed also to give a blood sample but 37 refused for cultural reasons.

After information about the project had been given in the local language, samples of blood and urine were collected for the same determinations from 202 randomly selected inhabitants of eight rural villages during an extensive epidemiological survey of the same region during the same period of time (3).

\section{Methods}

Goiters were graded by visual inspection and palpation according to WHO recommendations (9).

During the survey, blood and urine samples were obtained. The sequence of sampling was determined by random numbers. The collected samples were kept at $-20^{\circ} \mathrm{C}$ for the whole period of our stay in the Central African Republic and at $-10^{\circ} \mathrm{C}$ on our way back to Europe.

Urinary iodine concentration was measured in casual samples with a Technicon Autoanalyzer (10).

Thiocyanate concentration was evaluated using the method of Giraudi and Grillo (11).

Biochemical investigations performed included estimation of serum thyroid hormones: tri-iodothyronine $\left(\mathrm{T}_{3}\right)$, thyroxine $\left(\mathrm{T}_{4}\right)$, reverse tri-iodothyronine $\left(\mathrm{rT}_{3}\right)$, free thyroxine $\left(\mathrm{FT}_{4}\right)$, serum thyrotropin (TSH) and serum thyroglobulin (TG) all with commercial immunoassays (Biodata, Sorin (Saluggia, Italy) and Lepetit Sclavo (Milan, Italy)). The results were compared with reference values obtained in Italy in 100 healthy Ligurian subjects, whose median, median absolute deviations (MAD) and range were as follows: TSH $1.60 \quad(0.60) \quad 0.8-3.6 \mathrm{mU} / \mathrm{l} ; \quad \mathrm{T}_{3} \quad 2.3 \quad(0.3) \quad 1.08-$ $2.92 \mathrm{nmol} / \mathrm{l} ; \mathrm{T}_{4} 118$ (12) 60-143 nmol/l; $\mathrm{FT}_{4} 18.3$ (2.4) 7.7-21.9 pmol/l; $\begin{array}{rrrrr}\mathrm{rT}_{3} & 0.20 & (0.09) & 0.14-\end{array}$ $0.54 \mathrm{nmol} / \mathrm{l} ; \mathrm{T}_{3} / \mathrm{T}_{4}$ ratio $\left(\mathrm{T}_{3} / \mathrm{T}_{4} \times 1000\right) 19.0$ (3.6) 8.3-28.6; TG 13.2 (7.8) 9.6-18.0 $\mu \mathrm{g} / \mathrm{l}$; urinary iodine $0.60(0.06) 0.55-0.90 \mu \mathrm{mol} / \mathrm{l}$; urinary thiocyanate 23.3 (8.6) $19-29 \mu \mathrm{mol} / \mathrm{l}$.

Median and MAD were calculated for all biochemical parameters to overcome the non-Gaussian (or not normal) distribution of some of them. Statistical analysis was performed by the multiple comparisons method (Kruskal-Wallis).

A careful investigation was conducted by one of the authors ( J B) on the dietary habits of the Bororos with special emphasis on the daily consumption of milk and cassava.

\section{Results}

Data on the prevalence of goiter in the Bororos are shown in Table 1. The prevalence of goiter in the sample examined $(n=222)$ was $17.1 \%(3.6 \%$ in males and $13.5 \%$ in females) with a sex ratio (M/F) of 0.27 . Goiter was visible in only $1.35 \%$ of the subjects, diffuse in the great majority of them (95\%) and nodular in only $0.9 \%$ of the goitrous people. The prevalence of goiter was $18.6 \%$ in subjects younger than 15 years of age and $21 \%$ in women of childbearing age (16-45 years). No subject with goiter was observed in 34 people over 45 
Table 1 Prevalence of goiter (\%) according to sex in 222 Bororos and in 5453 subjects living in rural villages in the same area.

\begin{tabular}{|c|c|c|c|c|c|c|c|c|}
\hline \multirow[b]{2}{*}{ Subjects } & \multirow[b]{2}{*}{ Sex } & \multicolumn{6}{|c|}{ Goiter grade $(\%)$} & \multirow{2}{*}{$\begin{array}{c}\text { Goitrous } \\
(\%)\end{array}$} \\
\hline & & 0 & $1 a$ & $1 b$ & 2 & 3 & 4 & \\
\hline \multirow[t]{2}{*}{$\begin{array}{l}\text { Bororos } \\
(n=222)\end{array}$} & $\begin{array}{l}\text { Males } \\
(n=107 ; 48.2 \%)\end{array}$ & 92.5 & 5.6 & 1.9 & - & - & - & 7.5 \\
\hline & $\begin{array}{l}\text { Females } \\
(n=115 ; 51.8 \%)\end{array}$ & 73.9 & 20.0 & 3.5 & 2.6 & - & - & 26.1 \\
\hline \multirow[t]{2}{*}{$\begin{array}{l}\text { Rural villagers } \\
(n=5453)\end{array}$} & $\begin{array}{l}\text { Males } \\
(n=2655 ; 48.7 \%)\end{array}$ & 29.1 & 24.4 & 28.0 & 15.4 & 3.0 & 0.1 & 70.9 \\
\hline & $\begin{array}{l}\text { Females } \\
(n=2798 ; 51.3 \%)\end{array}$ & 17.4 & 17.2 & 27.9 & 25.3 & 11.2 & 1.0 & 82.6 \\
\hline
\end{tabular}

Using the classification recently introduced by WHO (29), the values for goiters of grade 1 and 2 were 15.8 and $1.3 \%$ and 48.7 and $28.3 \%$ for Bororos and rural villagers respectively.

years of age. These observations were compared with results of a contemporary epidemiological survey carried out in the same region in eight rural villages (Ngaoundaye, Man, Makele, Zole, Nzakoundou, Kounang, Ndim, De Gaule) in which the prevalence of goiter in subjects of the same age was $70.9 \%$ in males and $82.6 \%$ in females (Table 1).

The median value of urinary iodine concentration in 59 Bororos was $0.27 \mu \mathrm{mol} / \mathrm{l}$ compared with $0.60 \mu \mathrm{mol} / \mathrm{l}$ in the reference group $(P<0.001)$ and with $0.19 \mu \mathrm{mol} / \mathrm{l}$ in 84 subjects of the rural population $(P<0.01)$ (Table 2).

The median values of serum $\mathrm{T}_{3}, \mathrm{~T}_{4}, \mathrm{FT}_{4}, \mathrm{TSH}$ and $\mathrm{TG}$ obtained in 47 Bororo subjects were within their respective reference ranges; this was not the case for $\mathrm{T}_{3} / \mathrm{T}_{4}$ ratio and $\mathrm{rT}_{3}$ (Table 3 ). Nevertheless, with the exception of TG, all hormonal parameters were significantly different from the reference values $(P<0.01)$. In 18 subjects $(38 \%)$ serum $\mathrm{TSH}$ and $\mathrm{T}_{3} / \mathrm{T}_{4}$ ratio were moderately elevated above the upper limit of the reference range; in eight of them, serum $\mathrm{T}_{3}, \mathrm{~T}_{4}$ and $\mathrm{FT}_{4}$ were in the reference range, suggesting subclinical

Table 2 Levels of urinary iodine and thiocyanate in Bororo subjects compared with reference subjects and subjects living in rural villages in the same area. Values are expressed as median and MAD.

\begin{tabular}{lcc}
\hline Subjects & $\begin{array}{c}\text { lodine } \\
(\mu \mathrm{mol} / \mathrm{l})\end{array}$ & $\begin{array}{c}\text { Thiocyanate } \\
(\mu \mathrm{mol} / \mathrm{l})\end{array}$ \\
\hline Bororos & $\begin{array}{c}0.27(0.16) \\
(n=59)\end{array}$ & $\begin{array}{c}56.0(30.2) \\
(n=76)\end{array}$ \\
Rural villagers & $\begin{array}{c}0.19(0.08) \\
(n=84)\end{array}$ & $\begin{array}{c}103.4(48.3) \\
(n=99)\end{array}$ \\
Reference & $0.60(0.06)$ & $23.3(8.6)$ \\
& $(n=100)$ & $(n=100)$ \\
$P$ Bororos vs villagers & $<0.01$ & $<0.01$ \\
$P$ Bororos vs reference & $<0.001$ & $<0.01$
\end{tabular}

Statistical significances were calculated by the multiple comparison test (Kruskal-Wallis). hypothyroidism. No case of overt hypothyroidism was observed among the Bororos.

The median value of urinary thiocyanate concentration in 76 Bororos was $56 \mu \mathrm{mol} / \mathrm{l}$ compared with $23 \mu \mathrm{mol} / \mathrm{l}$ in 100 normal non-smoking subjects from the Ligurian population $(P<0.01)$ (Table 2$)$. In rural people for whom cassava is the staple food, the corresponding value for urinary thiocyanate was $103 \mu \mathrm{mol} / \mathrm{l}$ (Table 2).

\section{Discussion}

The Bororo population which is estimated to be 35000-40000 is spread over a very large region in the thinly peopled countries of the African continent. With some difficulty, 222 people, representative of the Bororos, were persuaded to come together in five villages from different parts of the savanna.

Undoubtedly, because of the small sample, the estimation of the prevalence of goiter may lack precision. Nevertheless, the impressive findings, confirmed by a recent survey organized by the national health authorities (Dr D Yazipo, President of the Regional Council of Health, 4th Health Region, personal communication), were first the high number of nongoitrous subjects, who normally roam through an iodine-deficient area where the prevalence of goiter in the rural villages is $76 \%$ for the total population and $82 \%$ for the schoolchildren $(3,4)$. Secondly, the pattern of the prevalence of goiter according to age, sex and grade of goiter in the Bororos was definitely different from observations made in other parts of Central Africa (12-15).

Among the Bororos a slight but non-significant rise in the prevalence of goiter was observed in females from puberty to 45 years, probably related to an increased need for iodine during pregnancy and lactation (16). However, no individual over the age of 45 was found to have goiter. These observations are partly in agreement with those reported by Clements et al., who observed in iodine-deficient areas a significant decrease in the 
Table 3 Levels of serum TSH, $\mathrm{T}_{3}, \mathrm{~T}_{4}, \mathrm{FT}_{4}, \mathrm{TG}, \mathrm{rT}_{3}$ and molar $\mathrm{T}_{3} / \mathrm{T}_{4}$ ratio in Bororo subjects compared with reference subjects and subjects living in rural villages in the same area. Values are expressed as median and MAD.

\begin{tabular}{lccccccc}
\hline Subjects & $\begin{array}{c}\mathbf{T S H} \\
(\mathrm{mU} / \mathrm{l})\end{array}$ & $\begin{array}{c}\mathbf{T}_{3} \\
(\mathrm{nmol} / \mathrm{l})\end{array}$ & $\begin{array}{c}\mathbf{T}_{4} \\
(\mathrm{nmol} / \mathrm{l})\end{array}$ & $\begin{array}{c}\mathbf{T}_{3} / \mathbf{T}_{4} \\
\mathbf{x ~ 1 0 0 0}\end{array}$ & $\begin{array}{c}\mathbf{F T}_{4} \\
(\mathrm{pmol} / \mathrm{l})\end{array}$ & $\begin{array}{c}\mathbf{T G} \\
(\mu \mathrm{g} / \mathrm{l})\end{array}$ & $\begin{array}{c}\mathbf{r T}_{3} \\
(\mathrm{nmol} / \mathrm{l})\end{array}$ \\
\hline $\begin{array}{l}\text { Bororos } \\
(n=47)\end{array}$ & $2.62(0.82)$ & $2.61(0.38)$ & $88(21)$ & $30.9(10.2)$ & $14.4(4.1)$ & $10.0(7.0)$ & $0.12(0.08)$ \\
$\begin{array}{l}\text { Rural villagers } \\
(n=193)\end{array}$ & $6.41(2.99)$ & $2.55(0.69)$ & $64(16)$ & $35.7(11.9)$ & $4.5(2.7)$ & $350.0(200.0)$ & $0.09(0.06)$ \\
$\begin{array}{l}\text { Reference } \\
(n=100)\end{array}$ & $1.60(0.60)$ & $2.30(0.30)$ & $118(12)$ & $19.0(3.6)$ & $18.3(2.4)$ & $13.2(7.8)$ & $0.20(0.09)$ \\
$\begin{array}{l}P \text { Bororos vs villagers } \\
P \text { Bororos vs reference }\end{array}$ & $<0.01$ & $\mathrm{~N} . \mathrm{S}$. & $<0.05$ & $\mathrm{~N} . \mathrm{S}$. & $<0.01$ & $<0.01$ & $\mathrm{~N} . \mathrm{S}$. \\
\hline
\end{tabular}

Statistical significances were calculated by the multiple comparison test (Kruskal-Wallis). N.S., Not significant.

prevalence of goiter in subjects older than 45 years particularly males (17-19). The very low prevalence of nodular goiter, associated with the absence of goiter over the age of 45 , suggests that diffuse goiters of small size (see grading in Table 1) return to a normal volume more rapidly than those we observed in the rural populations of Central Africa. The decrease in goitrogenic stimulation, particularly in women, during puberty and the period of fertility may account for this observation. This hypothesis is corroborated by a much lower frequency of pregnancy compared with that for black women living in the rural villages.

The median urinary iodine concentration was only $0.27 \mu \mathrm{mol} / \mathrm{l}$, a value intermediate between moderate and severe iodine deficiency (20). It was significantly lower $(P<0.001)$ than the median value obtained in our reference population but significantly higher than that $(0.19 \mu \mathrm{mol} / \mathrm{l})$ observed in subjects living in the same rural area $(P<0.01)$. This higher urinary iodine concentration in the Bororo shepherds may be explained by a higher iodine intake achieved during their migration. This, however, is unlikely since the countries through which they roam are all iodinedeficient and affected by endemic goiter and cretinism. Alternatively, one can speculate that their thyroid glands are more efficient in trapping or utilizing iodine and thus preventing enlargement.

Median values for thyroid function and thyroid related parameters observed in 47 Bororo subjects were all within the reference ranges except for the $\mathrm{T}_{3} / \mathrm{T}_{4}$ ratio and $\mathrm{rT}_{3}$ (Table 3). The hormonal concentrations in the Bororos were slightly lower than in the reference subjects, with a concomitant increase in serum TSH, $\mathrm{T}_{3}$ and $\mathrm{T}_{3} / \mathrm{T}_{4}$ ratio. These are classic indications of thyroid stimulation. In this respect, the observation of normal levels of TG, which is usually considered to be the most sensitive marker of the severity of iodine deficiency, is noteworthy. Such an observation indicates that TG correlates more closely with goiter grading $(19,21,22)$ than with TSH or its logarithm (23). Interestingly, in the rural villages where the prevalence of goiter was $76.9 \%$, only $8 \%$ of the subjects had a normal serum TG value (19).

Significant differences were observed between the Bororos and subjects from the rural villages (Table 3). The latter displayed a hormonal pattern that is classic for iodine deficiency. Thyroid function parameters were normal in $61.7 \%$ of the Bororos in contrast with only $15.3 \%$ in rural subjects from the same area.

The prevalence of goiter and the parameters of thyroid function in Bororos and in rural subjects were markedly different and unexpected on the basis of their relative urinary iodine concentrations. It was therefore reasonable to suspect the possible role of dietary factors particularly goitrogens.

Median urinary thiocyanate concentration in Bororos was about half that observed in rural subjects (Table 2) but significantly higher than that in the nonsmoking subjects used as reference. This observation is consistent with the observation that cassava is not a staple food for the Bororos as it is for rural subjects residing in villages where it is easily cultivated. A low intake of cyanogenic glucosides present in cassava tubers and metabolized into thiocyanate by liver enzymes may explain the partial inhibition of thyroidal iodine uptake, the disposal of which for hormone synthesis is clearly superior to that observed in the rural populations (24). It has been shown that, in the presence of a goitrogenic diet, the development of goiter is critically related to the balance between dietary supply of iodine and thiocyanate (25). However, in the Bororos, the higher iodine/thiocyanate ratio resulting from a slightly higher intake of iodine and lower intake of thiocyanate cannot account for the whole difference observed from subjects living in rural villages. Even a moderately higher intake of iodine associated with totally different eating habits (animal blood consumption and a diet rich in protein and lipid but poor in cassava and thiocyanate) may explain the absence of cretinism, the low prevalence of goiter and a high frequency of individuals with biochemical euthyroidism. The nutritional conditions of Bororos are very 
similar to those reported for the Tutsi from Rwanda, another shepherd group from Eastern Africa with a low prevalence of goiter (26). The frequent consumption of milk and cheese is most likely a beneficial factor since iodide is concentrated by the mammary gland (27). In contrast, poor socioeconomic conditions such as those prevailing for the rural people who eat cassava as the staple diet may be a promoting factor in goitrogenesis (28).

Although goiter and abnormalities of thyroid function are not at present frequent in the Bororos, they are probably at risk of iodine deficiency. In particular, a sedentary lifestyle would unavoidably be accompanied by an increase in consumption of cassava and therefore an increase in frequency of goiter.

Finally, our data confirm that assessment of iodine deficiency disorders cannot rely solely on the measurement of urinary iodine. They again demonstrate that evaluation of the iodine status of a population should not only include determination of urinary iodine concentrations but also evaluation of thyroid function parameters, goitrogenic factors and nutritional conditions.

\section{Acknowledgements}

The authors are indebted to the Sisters and Fathers of the Catholic Mission of Ndim, Bocaranga and Ngaoundaye for invaluable help given during the study. They give grateful thanks to Dr Maria Ludovica Piombino of the Ethnological Sciences Department of Genoa University for her specific contribution and Professor Maria Vittoria Gianelli for her English editorial assistance. This work was supported by the Fonds de la Recherche Scientifique Médicale Belge (Convention no 3.4505.97 to P B).

\section{References}

1 Ekpechi OL. Iodine deficiency disorders in Africa. In The Prevention and Control of Iodine Deficiency Disorders, pp 219-236. Eds B Hetzel, J Dunn \& JB Stanbury. Amsterdam: Elsevier, 1987.

2 Ermans AM, Thilly C, Vis HL \& Delange F. Permissive nature of iodine deficiency in the development of endemic goiter. In Endemic Goiter, pp 101-117. Ed JB Stanbury. Washington D.C.: Pan American Health Organization, Scientific Publication No 193, 1969.

3 Biassoni P, Schenone F, Ravera G, Balestra V, Green J \& Bertocchi J. Ouham Pendé: a new endemic goiter area in the Centro African Republic (CAR). Epidemiology survey on 7621 subjects. Thyroidology 19902 73-80.

4 Biassoni P, Schenone F, Bertocchi J, Green J, Mela G \& Balestra V. Ouham-Pendé: a new endemic goiter area in the Centro African Republic (CAR). Preliminary observations on school children. Thyroidology 19902 35-40.

5 Paulme D. Le Civilta Africane. Milano: Garzanti, 1958.

6 Prioul Ch. Eleveurs Nomades et Paysans Sédentaires dans Le Nord-ouest Centroafricain. Bordeaux: CEGET, 1971.

7 Brandt H. Nomades du Soleil. Lausanne: Clairfontaine, 1956.

8 Toso C. I Panà del Centrafrica-Storia, Societa, Religione. Roma: Publ. da Istituto Italo Africano, 1981.

9 De Mayer EM, Lowenstein FW \& Thilly CH. The Control of Endemic Goiter. Geneva: Monograph WHO, 1979.
10 Bourdoux P. Measurement of iodine in the assessment of iodine deficiency. IDD Newsletter 19884 8-12.

11 Giraudi G \& Grillo C. Direct spectrophotometric determination of thiocyanates in serum and urine with a continuous flow analyzer. Analytica Chimica Acta 1981128169.

12 Kambal A. Endemic goiter in the Sudan. Sudan Medical Journal $1968674-78$.

13 Greig WR, Gray HW, Mc Girr EM, Kambal A \& Rahaman IA. Investigations of endemic goiter in Sudan. British Journal of Surgery $19705711-16$.

14 Aquaron R, Poll-Gouater EP, Riviere R, Le Bras J \& Menard JC. Etude biologique du goitre endémique dans le pays Bamoun (Cameroun). Médecine d'Afrique Noire 197724 183-190.

15 Lagasse R, Luvivila K, Yunga Y, Gerard M, Hanson A, Bourdoux P \& Delange F. Endemic goitre and cretinism in Ubangi. In Role of Cassava in the Etiology of Endemic Goitre and Cretinism, pp 45-60. Eds AM Ermans, NM Bulamoko, F Delange \& R Ahluwalia. Ottawa: IDRC Monography - 136e, 1980.

16 Glinoer D, Delange F, Laboureur I, De Nayer P, Lejeune B, Kinthaert J \& Bourdoux P. Maternal and neonatal thyroid functions at birth in conditions of marginally low iodine intake. Journal of Clinical Endocrinology and Metabolism 199275 800-805.

17 Olesen RW. Iodine deficiency and prevalence of single goiter in Michigan. Journal of the American Medical Association 192482 1328-1332.

18 Clements FW, Gibson HB \& Howeler-Coy JF. Goiter studies in Tasmania. Bulletin WHO 196838297.

19 Biassoni P, Ravera G, Schenone F, Green J \& Bertocchi J. Hormonal and biochemical patterns in subjects from a new endemic goiter area in Central African Republic. Thyroidology 19913 63-68.

20 Bourdoux P \& Ermans AM. Quantitative assessment of iodine deficiency: a proposed classification. AOTA Symposium on Iodine Deficiency Disorders, April 1989, Tianjin, China, 1989, Abstract N-90.

21 Torrigiani G, Doniach D \& Roitt IM. Serum thyroglobulin levels in healthy subjects and in patients with thyroid diseases. Journal of Clinical Endocrinology and Metabolism 196929 305-309.

22 Pezzino V, Vigneri R, Squatrito S, Filetti S, Camus M \& Polosa P. Increased serum thyroglobulin levels in patients with non toxic goiter. Journal of Clinical Endocrinology and Metabolism 197846 653-657.

23 Van Herle AJ. Measurement and clinical significance of thyroglobulin in serum and body fluids. In Werner's The Thyroid, 5th edition, pp 534-545. Eds SH Ingbar \& LE Braverman. Philadelphia: Lippincot, 1986.

24 Bourdoux P, Delange F, Gerard M, Mafuta M, Hanson A \& Ermans AM. Evidence that cassava ingestion increased thiocyanate formation, a possible etiologic factor in endemic goiter. Journal of Clinical Endocrinology and Metabolism 197846 613-621.

25 Courtois P, Bourdoux P, Lagasse R, Ermans AM \& Delange F. Role of the balance between the dietary supplies of iodine and thiocyanate in the etiology of endemic goitre in the Ubangi area. In Nutritional Factors Involved in the Goitrogenic Action of Cassava, pp 65-69. Eds F Delange, FB Iteke \& AM Ermans. Ottawa: IDRC Monography-184e, 1982.

26 Vis HL, Yourassowsky C \& Van Der Borght H. A nutritional survey in the Republic of Rwanda. Annales du Musée Royal de l'Afrique Centrale-Sciences Humaines 197587 1-192.

27 Brown-Grant K. Extrathyroidal iodide concentrating mechanisms. Physiological Reviews 196141 189-213.

28 Ingenbleek Y. Thyroid dysfunction in protein-calorie malnutrition. Nutrition Reviews $198644253-263$.

29 WHO. Indicators for assessing iodine deficiency disorders and their control through salt iodization. WHO/NUT/94·6. Geneva: WHO, 1994.

Received 7 November 1997

Accepted 23 February 1998 